\title{
THYROID FUNCTION OF FORMER OPIOID ADDICTS ON NALTREXONE TREATMENT
}

\author{
Ioannis Ilias $^{1}$, Ioannis Kakoulas ${ }^{1}$, Ioulia Christakopoulou ${ }^{2}$, Kyriakos Katsadoros ${ }^{1}$ \\ «Klimax»- Support Foundation for the Socially Excluded, Athens, Greece'; «Sotiria» Hospital, Athens, Greece: \\ Department of Nuclear Medicine ${ }^{2}$
}

\begin{abstract}
Summary: In order to assess thyroid function in former opioid addicts undergoing adjunctive naltrexone (NA) p.o. treatment, we studied 24 subjects (BMI \pm SD: $23.3 \pm 3.2 \mathrm{~kg} / \mathrm{m}^{2}$ ) on $50 \mathrm{mg}$ NA p.o. daily for 15 days to 14.5 months continuously. Measurements included thyrotropin (TSH), total thyroxin (TT4), total triiodothyronine (TT3), while the TT3/TT4100 ratio was calculated as a marker of peripheral conversion of T4 to T3. Reverse T3 (rT3) and serum interleukin-6 (IL-6) levels were also measured. Statistical analysis of thyroid parameters among them, of thyroid parameters versus duration of NA use as well as of thyroid parameters versus BMI was done with linear regression. All the subjects received NA well. The thyroid hormone work-up showed that all the subjects on NA were overall euthyroid. Mean \pm SD levels for TSH were $1.59 \pm 0.29 \mathrm{mU} / \mathrm{L}$, TT4: $171.17 \pm 14.07 \mathrm{nmol} / \mathrm{L}$, TT3: $2.01 \pm 0.27 \mathrm{nmol} / \mathrm{L}$, TT3/TT4100: $1.18 \pm 0.19, \mathrm{rT} 3: 0.26 \pm 0.07 \mathrm{nmol} / \mathrm{L}$ and IL-6: $20.3 \pm 36.6 \mathrm{pg} / \mathrm{mL}$. The duration of NA use was positively correlated with TT3 $(\mathrm{r}=+0.72, \mathrm{p}<0.001)$ and TT3/TT4x100 $(\mathrm{r}=+0.77, \mathrm{p}<0.001)$ and negatively, but not statistically significant, with TT4 $(\mathrm{r}=-0.38, \mathrm{p}=0.065)$ and with TSH ( $\mathrm{r}=-0.39$, $\mathrm{p}=0.062$ ). No significant correlations were found between TT3 and BMI, duration of NA use and rT3 and IL-6. Although few subjects were studied, there are indications that the duration of naltrexone may be positively correlated with TT3 and the ratio of $\mathrm{T} 4$ to $\mathrm{T} 3$ conversion.
\end{abstract}

Key words: Heroin dependence; Narcotic antagonists; Naltrexone therapeutic use; Naltrexone adverse effects; Blood thyroid hormones

\section{Introduction}

Naltrexone hydrochloride (NA) is an opioid antagonist, used p.o. as a non-addicting, long-acting adjunctive medication for the treatment of detoxified opiate addicts (15) and alcohol dependence (6). Although NA is considered to have minor or no effects on the pituitary-thyroid axis (1), human studies on this subject are not abundant. The aim of this study was to assess, using mostly routine thyroid function measurements, the effect of NA use in - otherwise healthy - former opiate addicts.

\section{Subjects, materials and methods}

We studied in a cross-sectional fashion, 20 men and 4 women (mean age \pm SD: $26.6 \pm 2.9$ y.o., mean $\mathrm{BMI} \pm \mathrm{SD}$ : $23.3 \pm 3.2 \mathrm{~kg} / \mathrm{m}^{2}$ ) who were former opiate addicts (heroin abusers) and followed vocational training courses in Klimax (a non-government support foundation) in 1998-9. All the participants were solely on $50 \mathrm{mg}$ daily NA p.o. therapy continuously for 15 days to 14.5 months (mean duration $\pm \mathrm{SD}: 6.3 \pm 5.2$ ). All the subjects were in good clinical condition, did not suffer from psychiatric disorders necessitating medication, were $\operatorname{HBV}(-)$, HIV(-) and opioid-free (as- sessed with urine screening) for two weeks before commencing NA treatment and throughout its use. Opioid withdrawal was uneventful for all the subjects (slight anxiety and some flu-like symptoms). Blood sampling in all the subjects was done once between 09:00 and 11:00 hours, in order to avoid diurnal hormonal variations. Measurement of serum thyrotropin (TSH) was performed with an immunoradiometric assay (Clinical Assay Gammacoat hTSH ${ }^{125} \mathrm{I}$ IRMA Kit, Incstar Corporation, Minnesota, USA; interassay coefficient of variation $\left[\mathrm{CV}_{1}\right]: 4.0-5.7 \%$, intraassay coefficient of variation $\left[\mathrm{CV}_{2}\right]$ : $3.1-3.3 \%$, normal values: 0.30-3.70 mU/L). Serum levels of total thyroxin (TT4; $\mathrm{CV}_{1}$ : 3.6-4.7\%, $\mathrm{CV}_{2}$ : 2.6-3.2\%, normal values: $64.35-164.73$ $\mathrm{nmol} / \mathrm{L}$ ), and total triiodothyronine (TT3; $\mathrm{CV}_{1}: 3.2-4.9 \%$, $\mathrm{CV}_{2}: 1.6-3.7 \%$, normal values: $0.77-2.69 \mathrm{nmol} / \mathrm{L}$ ) were measured by radioimmunoassay (RIA) methods (Amerlex-M, Ortho-Clinical Diagnostics, Amersham, UK). The TT3/TT4x100 ratio was calculated as a marker of peripheral conversion of T4 to T3 $(7,12)$. Reverse T3 was measured with RIA (rT3 RIA, Biocode Biotechnology, Liege, Belgium; $\mathrm{CV}_{1}$ : 3.9-6.9\%, $\mathrm{CV}_{2}$ : 3.0-6.1\%, normal values: 0.231-0.539 nmol/L). Serum interleukin-6 (IL-6) was measured - in order to evaluate the level of inflammatory cytokine activation - with an enzymoimmunometric assay (Quan- 
tikine HS human IL-6 immunoassay, R\&D Systems, Oxon, England; $\mathrm{CV}_{1}: 6.7-29.5 \%, \mathrm{CV}_{2}: 3.8-11.1 \%$, normal values: $0.38-10.10 \mathrm{pg} / \mathrm{mL}$ ).

Statistical analysis of thyroid parameters among them, of thyroid parameters versus duration of NA use as well as versus BMI was done with linear regression, implementing the Bonferroni correction - since eight significance tests were applied - which set statistical significance at $\mathrm{p}=0.050 / 8 \simeq 0.006$.
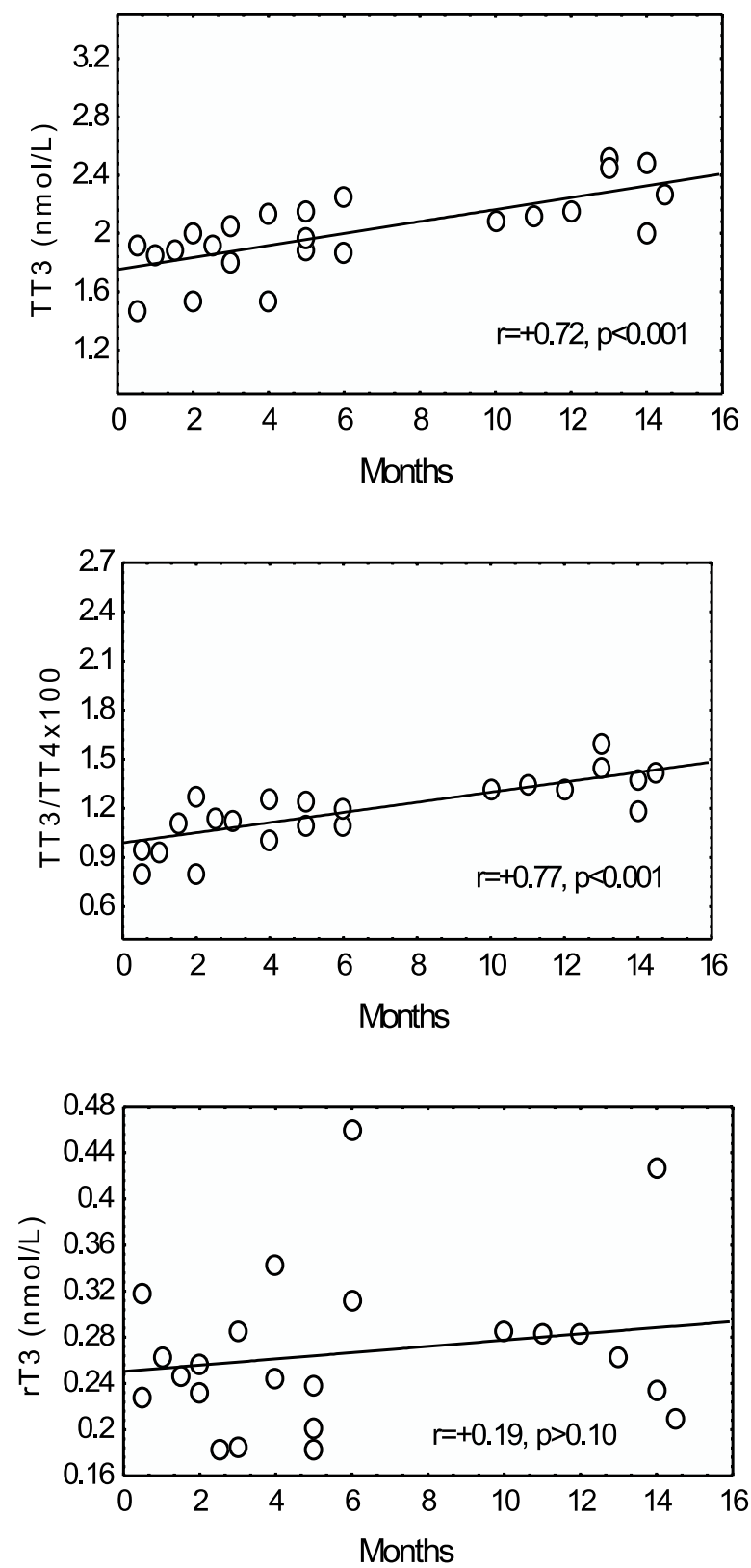

\section{Results}

All the subjects received NA well. The thyroid hormone work-up showed that all the subjects on NA were overall euthyroid. Mean \pm SD levels for TSH were $1.59 \pm 0.29 \mathrm{mU} / \mathrm{L}$, for TT4: $171.17 \pm 14.07 \mathrm{nmol} / \mathrm{L}$, for TT3: $2.01 \pm 0.27$ $\mathrm{nmol} / \mathrm{L}$ and for TT3/TT4T100: $1.18 \pm 0.19$. Mean \pm SD rT3 was $0.26 \pm 0.07 \mathrm{nmol} / \mathrm{L}$. Mean \pm SD IL- 6 was $20.3 \pm 36.6$ $\mathrm{pg} / \mathrm{mL}$. The duration of NA use was positively correlated
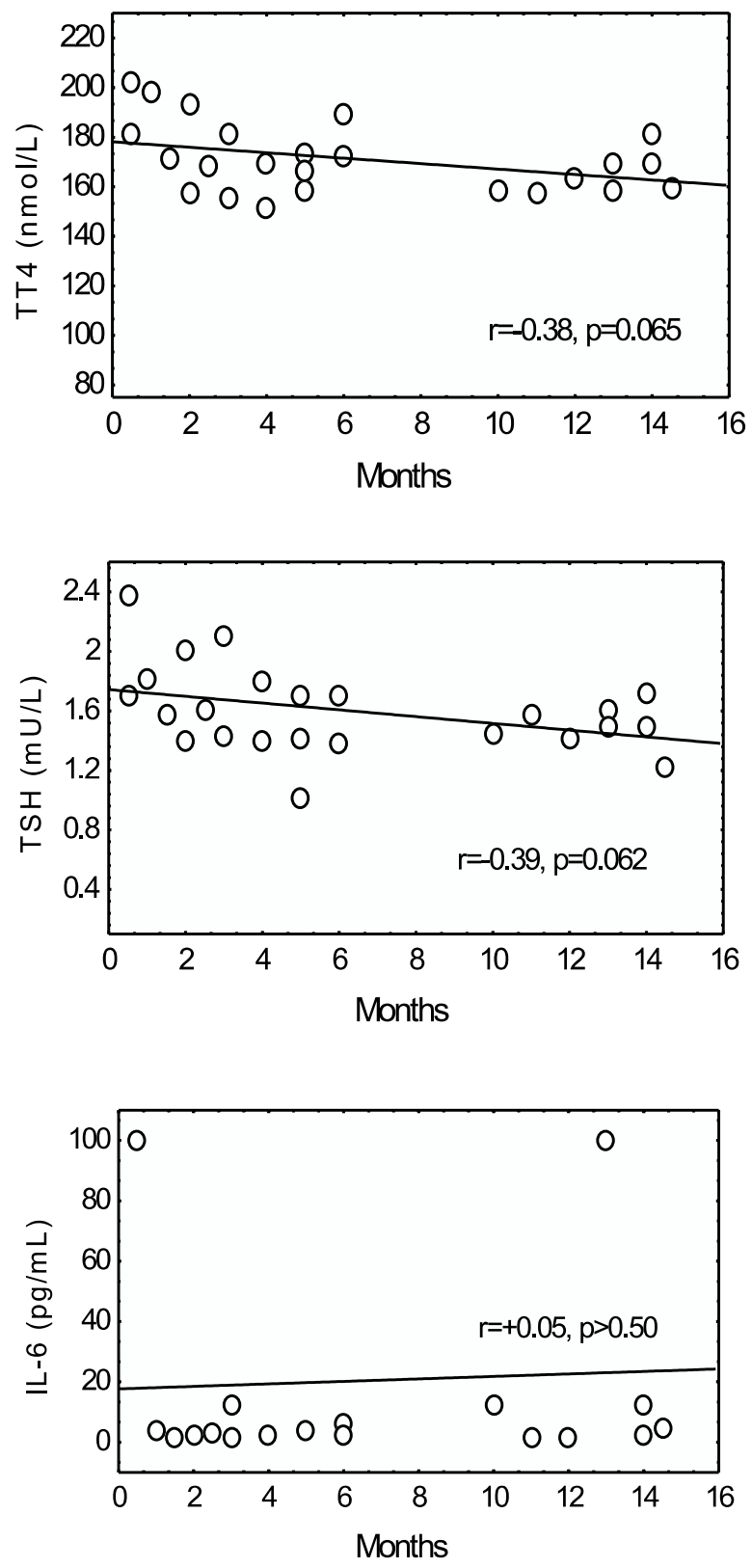

Fig. 1: Scatterplots of total triiodothyronine [TT3], total thyroxine [TT4], TT3/TT4(100 ratio [TT3/TT4(100], thyrotropin [TSH], reverse T3 [rT3] and interleukin-6 [IL-6] versus duration of naltrexone use, in months, in 24 subjects, each sampled once. 
with TT3 $(r=+0.72, \mathrm{p}<0.001)$ and TT3/TT4T100 $(r=+0.77$, $\mathrm{p}<0.001)$ and negatively, but not statistically significant, with TT4 $(\mathrm{r}=-0.38, \mathrm{p}=0.065)$ and with TSH $(\mathrm{r}=-0.39$, $\mathrm{p}=0.062)$. Lesser correlations were found for $\mathrm{rT} 3$ versus TT3( $r=+0.20, p>0.10)$, TT3 versus BMI $(r=+0.35, p>0.10)$, rT3 versus duration of NA use $(r=+0.19, p>0.10)$ and IL- 6 versus duration of NA use $(r=0.05, p>0.50)$ [figure 1].

\section{Discussion}

Our results indicate that subjects on NA are euthyroid, however, their TT3 levels and ratio of conversion of T4 to T3 are correlated with the duration of this medication's use. It is known that morphine may exert an inhibitory action on the hypothalamo-pituitary system, leading to decreased TSH secretion (14). Studies of heroin users have shown a slight increase in basal serum T3 levels - but not of T4 - and a blunted TSH rise after thyrotropin-releasing hormone (TRH) stimulation in $50 \%$ of subjects $(3,4,9)$. In a recent study in humans, serum T3 levels fell considerably and TSH responses to acute TSH-releasing hormone (TRH) administration were decreased, after infusion of naloxone (another opiate antagonist) (10). Rapid opiate detoxification in opiate addicts - under anesthesia, with opiate antagonists - induces the euthyroid sick syndrome, noted by lowering of serum TSH, T4 and T3 levels (8). The observed effects in our study could be attributed to an effect of NA analogous to that of opiate-induced TSH suppression, apparently mediated by receptors located both within and outside the blood brain barrier (in both the pituitary and thyroid cells) $(5,11)$. Although it has been shown that $\mu$-and $\delta$-opioid receptor blockade inhibits and stimulates, respectively, the secretion of IL-6 (2), which is known to contribute to the euthyroid sick syndrome (13), no correlation between IL-6 and duration of NA use was shown in this study. Another possibility is that the observed relationships of hormones versus duration of NA use were the result of the gradual recovery of pituitary-thyroid function occurring after heroin withdrawal (4), however, this idea is not supported by the lack of significant correlations between the duration of heroin withdrawal and rT3 and between BMI and TT3. Heroin abusers may be in a poor nutrition status and suffer from thrombophlebitis or other cutaneous infections, factors associated with the euthyroid sick syndrome. Subjects included in the present study, however, were not malnourished and had BMIs in the normal range.

This report has certain limitations. Among them we can point out the study type per se, which was cross-sectional and included few subjects. We did not include a control group, mainly because we were unable to find „normal“ subjects that had been withdrawn from heroin and also because we did not want to abstain from supporting former heroin abusers with adjunctive drug therapy, such as with NA. Another limitation of the study was that the thyroid parameters studied were overall found to be in the normal range.

In conclusion, although concrete evidence is pending, we believe that prescribing physicians should be aware that the use of NA may have effects on thyroid hormone levels.

\section{References}

1. Atkinson RL. Endocrine and metabolic effects of opiate antagonists. J Clin Psychiatry 1984;45:20-4

2. Bertolucci M, Perego C, De Simoni MG. Interleukin-6 is differently modulated by central opioid receptor subtypes. Am J Physiol 1997;273:R 956-9.

3. Brambilla F, Nobile P, Zanoboni A, Zanoboni-Muciaccia W, Meroni PL. Effects of chronic heroin addiction on pituitary-thyroid function in man. J Endocrinol Invest 1980; 3: 251-255.

4. Chan V, Wang C, Yeung RT. Effects of heroin addiction on thyrotrophin, thyroid hormones and prolactin secretion in men. Clin Endocrinol 1979;10:557-65.

5. del Valle-Soto ME, Iglesias L, Calzada B, Vega JA, Hernandez LC, Perez-Casas A. Effects of morphine on the pituitary-thyroid axis: morphological and analytical studies. Funct Dev Morphol 1991;1:3-6.

6. Garbutt JC, West SL, Carey TS, Lohr KN, Crews FT. Pharmacological treatment of alcohol dependence: a review of the evidence. JAMA 1999;281:1318-25.

7. Olivieri O, Girelli D, Stanzial AM, Rossi L, Bassi A, Carrocher R. Selenium, zinc, and thyroid hormones in healthy subjects: low T3/T4 ratio in the elderly is related to impaired selenium status. Biol Trace Elem Res 1996;51:31-41.

8. Pfab R, Hirtl C, Zilker T. Opiate detoxification under anesthesia: no apparent benefit but apparent suppression of thyroid hormones and risk of pulmonary and renal failure. J Toxicol Clin Toxicol 1999;37:43-50.

9. Rasheed A, Tareen IA. Effects of heroin on thyroid function, cortisol and testosterone level in addicts. Pol J Pharmacol 1995;47:441-4.

10. Samuels MH, Kramer P, Wilson D, Sexton G. Effects of naloxone infusions on pulsatile thyrotropin secretion. J Clin Endocrinol Metab 1994;78:1249-52.

11. Simpkins JW, Swager D, Millard WJ. Evaluation of the sites of opioid influence on anterior pituitary hormone secretion using a quaternary opiate antagonist. Neuroendocrinology 1991;54:384-90.

12. Smith SJ, Bos G, Gerbrandy J, Docter R, Visser TJ, Hennemann G. Lowering of serum 3, 3', 5-triiodothyronine thyroxine ratio in patients with myocardial infarction; relationship with extent of tissue injury. Eur J Clin Invest 1978;8:99-102.

13. Stouthard JML, Van der Poll T, Endert E et al. Effects of acute and chronic interleukin-6 administration on thyroid hormone metabolism in humans. J Clin Endocrinol Metabol 1994;79:1342-6.

14. Tal E, Koranyi L, Kovacs Z, Endroczi E. Short-term effect of morphine on the thyroid gland in male rats. Acta Endocrinol 1984;105:511-4.

15. Ward J, Hall W, Mattick RP. Role of maintenance treatment in opioid dependence. Lancet 1999;353:221-6.

Submitted August 2000.

Accepted January 2001.

Dr. Ioannis Ilias,

129, Kifissias Avenue, Athens,

GR-11524, GREECE.

e-mail: ilias@compulink.gr 